\title{
Role of Vitamin D Deficiency in Allergic Diseases: Is this Due to an Impaired Patients' Response to Corticosteroid Therapy?
}

\author{
Ian Adcock ${ }^{1}$ and Yassine Amrani ${ }^{2 *}$ \\ ${ }^{1}$ Airways Disease Section, National Heart \& Lung Institute Imperial College London, London \\ ${ }^{2}$ Department of Infection, Immunity and Inflammation, University of Leicester, UK
}

Received: February 13, 2014; Accepted: February 14, 2014; Published: February 17, 2014

*Corresponding author: Yassine Amrani, Institute for Lung Health, Department of Respiratory Medicine, Clinical Sciences Building, Glenfield Hospital, Groby Rd, Leicester, LE3 9QP, UK, Tel: +44-116-256-3794; Fax: +44-116-250-2787; E-mail: ya26@le.ac.uk

\section{Introduction}

Accumulating evidence now shows that low level of vitamin D is associated with the development and/or aggravation of a number of lung diseases in both adults and children [1-3]. Clinically, low levels of vitamin D refers to hormone deficiency which is defined by a serum level $<20 \mathrm{ng} / \mathrm{mL}$ [4]. Vitamin $D$ insufficiency, typically defined by levels ranging from 20-29ng/ $\mathrm{mL}$, has also been regarded as clinically important particularly in children [5]. Despite numerous reports associating vitamin D levels to allergic disorders, the cellular and molecular pathways explaining the protective role of vitamin D in lung diseases have not been fully investigated. The purpose of this short review is to describe the current evidence describing the importance of vitamin D in modulating patient's response to corticosteroid therapy.

\section{Lower Levels of Vitamin D Correlate with Severity of Allergic Lung Diseases}

A number of epidemiological studies from different countries have led to the same conclusion that low levels of vitamin D is associated with asthma in both children and adults. Studies performed in asthmatic children led to the demonstration that vitamin D insufficiency $(<30 \mathrm{ng} / \mathrm{mL})$ was associated with asthma exacerbations and poor lung function in Puerto Rican patients [6] or poor asthma control and lung function in a British cohort [7]. In contrast, Wu AC, et al. [8] found that vitamin D deficiency rather than insufficiency was a feature in asthmatic children with a poor lung function characterized by a reduced improvement in pre-bronchodilator $\mathrm{FEV}_{1}$ after inhaled corticosteroid treatment over the course of 1 year when compared to hormone sufficient patients [8]. A larger study involving 1024 children with mildto-moderate persistent asthma from a multicentre clinical trial also found that higher odds of hospitalization and emergency department visits correlate with serum levels of vitamin D below $<30 \mathrm{ng} / \mathrm{mL}$ [9]. A more recent study by Bener A, et al. [10], conducted in Qatari children revealed that vitamin D deficiency was the strongest predicator of asthma although a deficiency in phosphorus or magnesium was also noticed in these patients [10]. In a cohort of Italian children (5-11 year-old), patients with partially controlled or uncontrolled asthma had insufficient levels of vitamin D while those with higher vitamin D levels had their disease well-controlled [11]. In a different study the same group described a poor lung response and $>10 \% \mathrm{FEV}_{1}$ change in response to exercise challenge in children with intermittent asthma who had vitamin D insufficiency [12]. It is also important to mention that not all studies have found a correlation between low vitamin D levels and severity or the level of asthma control in children $[13,14]$.

In addition to asthmatic children, vitamin D deficiency was also shown to impact on disease severity in adults. In a cohort of non-smoking adults with asthma, Sutherland ER, et al. [15], reported that patients with insufficient levels of vitamin D had increased airway sensitivity to methacholine challenge while patients with higher vitamin D levels had greater lung function [15]. Among the cohort of 121 Costa Rican patients, it was found that $74 \%$ of those with a vitamin D insufficiency or $91 \%$ of those with a vitamin $\mathrm{D}$ deficiency had higher risks of developing a severe disease. In contrast, those with higher levels of vitamin D were protected against the risk of hospitalizations or emergency room visits [16]. A German study involving 280 patients recently confirmed that serum levels of vitamin $\mathrm{D}<30 \mathrm{ng} / \mathrm{mL}$ were more prevalent among adult patients with severe and/or uncontrolled asthma and were linked to lower forced expiratory volume in the first one second $\left(\mathrm{FEV}_{1}\right)$ and sputum eosinophilia [17]. A similar observation linking low levels of vitamin $\mathrm{D}$ and poor lung function assessed by air flow limitation was reported in a Chinese cross-sectional study involving 435 patients [18].

Taken together, these epidemiological studies from different parts of the globe reinforced the concept that the lack of vitamin D may have detrimental consequences on the management of asthmatic patients. It has been proposed that this could be due to a loss of the steroid-enhancing anti-inflammatory properties of vitamin D. 


\section{Vitamin D and Corticosteroid Therapy in Asthma}

The observation that levels of vitamin D were important in determining in vitro corticosteroid responsiveness and steroid requirements in asthmatic children strongly suggested that vitamin D directly or indirectly regulates the therapeutic responses of corticosteroids [19]. A study by Searing and colleagues in asthmatic children showed that patients with low levels of vitamin D not only presented with worse airflow obstruction but also had an increased need for inhaled and oral corticosteroids [20]. In addition, these authors found that combining vitamin D and dexamethasone was effective in inhibiting ex vivo steroid-resistant features such as $\mathrm{T}$ cell proliferation, raising the possibility that supplementation with vitamin $\mathrm{D}$ could be effective in restoring steroid efficacy.

An earlier study convincingly showed that in the presence of vitamin $\mathrm{D}$, dexamethasone was able to induce secretion of the anti-inflammatory cytokine IL-10 by CD4+ T cells isolated from steroid-insensitive patients. This suggests that vitamin $\mathrm{D}$ is able to reinstate corticosteroid responsiveness, at least ex vivo, seen in steroid resistant conditions [21]. The potential role of vitamin D in managing steroid insensitive conditions was further suggested by Nanzer AM, et al. [22]. IL-17 expression is increased in steroidinsensitive asthmatic patients, however, vitamin D treatment suppressed the production of dexamethasone-resistant IL-17 by peripheral blood mononuclear cell (PBMCs) [22]. Furthermore, there was a superior damping of LPS responses of combining vitamin $\mathrm{D} /$ dexamethasone compared to individual treatments in PBMCs taken from patients who were either sensitive or resistant to corticosteroid therapy [23].

The greater therapeutic benefit provided by vitamin D/ corticosteroid combination could possibly result from an enhanced corticosteroid receptor (GR) signalling. This hypothesis was recently supported by the observation that vitamin D/ corticosteroid led to an increased induction of the GR-inducible anti-inflammatory protein called MAPK phosphatase 1 gene [24]. Another interesting anti-inflammatory protein induced by vitamin D/corticosteroid combination is IL-10. A study performed in children defined as severe-therapy resistant asthma reported a positive correlation between systemic levels of vitamin $\mathrm{D}$ and levels of IL-10 present in the bronchoalveolar lavage fluids. Although the underlying mechanisms of this association are not known, the authors showed that vitamin D was able to enhance IL10 production induced by dexamethasone in PBMCs from these patients [25]. The role of IL-10 in the anti-inflammatory action of vitamin D has been previously described by Hawrylowicz CM's group [26-28], which showed that vitamin D significantly increased production of IL-10 by Foxp $3+\mathrm{T}$ regulatory (Treg) cells [26-28]. Interestingly, a positive correlation was also found between serum vitamin D levels and circulating IL$10+$ Treg cells in asthmatic children [29]. These findings support previous observations made in patients suffering from Crohn's disease where vitamin D increased IL-10 while inhibiting IFN $\gamma$ production in CD4+ T cells [30], providing further evidence for its therapeutic potential in managing other inflammatory diseases.
These studies provide undeniable in vitro/ex vivo evidence of a role of vitamin $\mathrm{D}$ in regulating corticosteroid responses via mechanisms that remain to be elucidated. The use of vitamin D as therapeutic supplement in asthmatics, therefore, suggested by multiple lines of evidence including that vitamin D inhibits steroid-resistant features and possesses immunemodulatory actions possibly via the regulation of Treg cells. More importantly, vitamin D also exhibits steroid-enhancing properties. These studies raise the interesting possibility that vitamin D supplementation could lead to a better control of asthma, in part by enhancing corticosteroid responsiveness particularly in patients with severe disease.

\section{Acknowledgement}

Supported by the National Institute for Health Research Leicester Respiratory Biomedical Research Unit. The views expressed are those of the author(s) and not necessarily those of the NHS, the NIHR and by Department of Health.

\section{References}

1. Gupta A, Bush A, Hawrylowicz C, Saglani S (2012) Vitamin D and asthma in children. Paediatric Respiratory Reviews 13(4): 236-243.

2. Poon AH, Mahboub B, Hamid Q (2013) Vitamin D deficiency and severe asthma. Pharmacol Ther 140(2): 148-155.

3. Frieri M, Valluri A (2011) Vitamin D deficiency as a risk factor for allergic disorders and immune mechanisms. Allergy Asthma Proc 32(6): 438-444

4. Norman PE, Powell JT (2014) Vitamin D and cardiovascular disease. Circulation Research 114: 379-393.

5. Greer FR (2009) Defining vitamin D deficiency in children: beyond 25$\mathrm{OH}$ vitamin D serum concentrations. Pediatrics 124(5): 1471-1473.

6. Brehm JM, Acosta-Perez E, Klei L, Roeder K, Barmada M, et al. (2012) Vitamin D insufficiency and severe asthma exacerbations in Puerto Rican children. Am J Respir Crit Care Med 186(2): 140-146.

7. Gupta A, Sjoukes A, Richards D, Banya W, Hawrylowicz C, et al. (2011) Relationship between serum vitamin D, disease severity, and airway remodeling in children with asthma. Am J Respir Crit Care Med 184(12): 1342-1349.

8. Wu AC, Tantisira K, Li L, Fuhlbrigge AL, Weiss ST, et al. (2012) Effect of vitamin D and inhaled corticosteroid treatment on lung function in children. Am J Respir Crit Care Med 186(6): 508-513.

9. Brehm JM, Schuemann B, Fuhlbrigge AL, Hollis BW, Strunk RC, et al. (2010) Serum vitamin D levels and severe asthma exacerbations in the Childhood Asthma Management Program study. J Allergy Clin Immunol 126(1): 52-58.

10. Bener A, Ehlayel MS, Tulic MK, Hamid Q (2012) Vitamin D deficiency as a strong predictor of asthma in children. Int Arch Allergy Immunol 157(2): 168-175.

11. Chinellato I, Piazza M, Sandri M, Peroni D, Piacentini G, et al. (2011) Vitamin D serum levels and markers of asthma control in Italian children. J Pediatr 158(3): 437-441.

12. Chinellato I, Piazza M, Sandri M, Peroni DG, Cardinale F, et al. (2011) Serum vitamin D levels and exercise-induced bronchoconstriction in children with asthma. Eur Respir J 37(6): 1366-1370.

13. Menon J, Maranda L, Nwosu BU (2012) Serum 25-hydroxyvitamin D 
levels do not correlate with asthma severity in a case-controlled study of children and adolescents. J Pediatr Endocrinol Metab 25(7): 673679.

14. Krobtrakulchai W, Praikanahok J, Visitsunthorn N, Vichyanond P, Manonukul K, et al. (2013) The effect of vitamin d status on pediatric asthma at a university hospital, Thailand. Allergy Asthma Immunol Res 5(5): 289-294.

15. Sutherland ER, Goleva E, Jackson LP, Stevens AD, Leung DYM (2010) Vitamin D levels, lung function, and steroid response in adult asthma. Am J Respir Crit Care Med 181(7): 699-704.

16. Montero-Arias F, Sedo-Mejia G, Ramos-Esquivel A (2013) Vitamin d insufficiency and asthma severity in adults from costa rica. Allergy Asthma Immunol Res 5(5): 283-288.

17. Korn S, Hubner M, Jung M, Blettner M, Buhl R (2013) Severe and uncontrolled adult asthma is associated with vitamin D insufficiency and deficiency. Respir Res 14(1): 25.

18. Li F, Peng M, Jiang L, Sun Q, Zhang K, et al. (2011) Vitamin D deficiency is associated with decreased lung function in Chinese adults with asthma. Respiration 81(6): 469-475.

19. Goleva E, Searing DA, Jackson LP, Richers BN, Leung DY (2012) Steroid requirements and immune associations with vitamin $D$ are stronger in children than adults with asthma. J Allergy Clin Immunol 129(5): 1243-1251.

20. Searing DA, Zhang Y, Murphy JR, Hauk PJ, Goleva E, et al. (2010) Decreased serum vitamin D levels in children with asthma are associated with increased corticosteroid use. J Allergy Clin Immunol 125(5): 995-1000.

21.Xystrakis E, Kusumakar S, Boswell S, Peek E, Urry Z, et al. (2006) Reversing the defective induction of IL-10-secreting regulatory T cells in glucocorticoid-resistant asthma patients. J Clin Invest 116(1): 146155 .

22. Nanzer AM, Chambers ES, Ryanna K, Richards DF, Black C, et al.
(2013) Enhanced production of IL-17A in patients with severe asthma is inhibited by $1 \alpha, 25$-dihydroxyvitamin D3 in a glucocorticoidindependent fashion. J Allergy Clin Immunol 132(2): 297-304.

23.Zhang Y, Goleva E, Leung DYM (2010) Vitamin D has corticosteroid sparing effects by enhancing glucocorticoid induced mitogen-activated protein kinase phosphatase-1. J Allergy Clin Immunol 125(2): Ab54.

24. Zhang Y, Leung DY, Goleva E (2013) Vitamin D enhances glucocorticoid action in human monocytes involvement of granulocyte-macrophage colony-stimulating factor and mediator complex subunit 14. J Biol Chem 288(20): 14544-14553.

25. Gupta A, Dimeloe S, Richards DF, Chambers ES, Black C, et al. (2013) Defective IL-10 expression and in vitro steroid-induced IL-17A in paediatric severe therapy-resistant asthma. Thorax doi:10.1136/ thoraxjnl-2013-203421.

26. Urry Z, Chambers ES, Xystrakis E, Dimeloe S, Richards DF, et al. (2012) The role of 1a,25-dihydroxyvitamin D3 and cytokines in the promotion of distinct Foxp3+and IL-10+CD4+ T cells. Eur J Immunol 42(10): 2697-2708.

27. Chambers ES, Urry Z, Nanzer AM, Richards DF, Gupta A, et al. (2012) Vitamin D increases the frequency of FoxP3+ Tregs in vitro and in vivo: differential role for IL-2 and IL-10. Immunology 137: 84.

28. Urry Z, Xystrakis E, Dimeloe S, Richards DF, Brown Z, et al. (2010) 1a,25-dihydroxyvitamin D3 differentially promotes Foxp3 and IL-10 expression by human CD4+T cells. Immunology 131: 184.

29. Maalmi H, Berraies A, Tangour E, Ammar J, Abid H, et al. (2012) The impact of vitamin D deficiency on immune $\mathrm{T}$ cells in asthmatic children: a case-control study. J Asthma Allergy 5: 11-19.

30. Bartels LE, Jorgensen SP, Agnholt J, Kelsen J, Hvas CL, et al. (2007) 1,25-dihydroxyvitamin D3 and dexamethasone increase interleukin-10 production in CD4+ T cells from patients with Crohn's disease. Int Immunopharmacol 7(13): 1755-1764. 